\title{
Fast-Track Programs Versus Traditional Care in Hepatectomy: A Meta-Analysis of Randomized Controlled Trials
}

\author{
Qiucheng Lei ${ }^{a}$ Xinying Wang ${ }^{a, b}$ Shanjun Tan ${ }^{b}$ Xianfeng Xia ${ }^{b}$ \\ Huazhen Zheng ${ }^{\mathrm{c}}$ Chao $\mathrm{Wu}^{\mathrm{b}}$ \\ aDepartment of General Surgery, Jinling Hospital, Southern Medical University, Nanjing, Jiangsu Province, \\ ${ }^{\mathrm{b}}$ Research Institute of General Surgery, Jinling Hospital, Medical School of Nanjing University, Nanjing, Jiangsu \\ Province, and 'Key Laboratory for Medical Molecular Diagnostics of Guangdong Province, Guangdong Medical \\ College, Dongguan, Guangdong Province, China
}

\section{Key Words}

Fast track · Enhanced recovery after surgery - Liver

resection $\cdot$ Hepatectomy $\cdot$ Meta-analysis

\begin{abstract}
Background/Aims: The role of fast-track programs in hepatectomy is unclear. This meta-analysis aimed to evaluate the efficacy and safety of fast-track programs versus traditional care. Methods: We searched Pubmed, Embase, Cochrane Central Register of Controlled Trials, and Google Scholar for relevant randomized controlled trials (RCTs) comparing fasttrack with traditional care in hepatectomy. Length of hospital stay, time to first flatus, postoperative complications, operating time, and intraoperative blood loss were assessed. Meta-analyses were performed using RevMan 5.2 software. Results: Four original RCTs with 372 patients were included: 187 in the fast-track and 185 in the traditional care group. Fast-track patients had shorter hospital stay (WMD -2.32; $95 \% \mathrm{Cl},-3.54$ to $-1.11 ; \mathrm{p}<0.001)$ and time to first flatus (WMD $-0.99 ; 95 \% \mathrm{Cl},-1.15$ to $-0.84 ; \mathrm{p}<0.001$ ), and less postoperative complications (RR $0.66 ; 95 \% \mathrm{Cl}, 0.47$ to $0.93 ; \mathrm{p}<$
\end{abstract}

0.05). However, there was significant heterogeneity between the studies regarding hospital stay $\left(\mathrm{I}^{2}=88 \%\right.$; $\mathrm{p}<$ 0.001). Operating time and intraoperative blood loss were not different. Conclusions: Patients in fast-track programs had less time to first flatus and postoperative complications compared to traditional care. Fast-track programs may reduce the length of hospital stay. Larger, higher quality prospective RCTs are necessary to draw more robust conclusions.

(c) 2014 S. Karger AG, Base

\section{Introduction}

Fast-track (FT) programs, also called enhanced recovery after surgery (ERAS) or FT surgery, were introduced initially in colorectal surgery by Kehlet and his team in 1991 to attenuate surgical stress response and accelerate recovery $[1,2]$. FT programs involve multimodal perioperative strategies that include preoperative patient education, optimized anesthesia, early postoperative enteral nutrition, and early mobilization. Recently, anecdotal ev-

\section{KARGER}

E-Mail karger@karger.com

www.karger.com/dsu (c) 2014 S. Karger AG, Basel

0253-4886/14/0315-0392\$39.50/0 
idence suggested that FT programs are associated with beneficial clinical outcomes, such as shorter hospital stay, reduced hospital costs, and improved morbidity $[3,4]$.

Over the last decade, FT programs have been used in vascular surgery [5], breast surgery [6], urologic [7], and orthopedic surgery [8]. However, FT for liver surgery was first described in 2008 [9]. Since then, several studies assessing FT programs in liver resection have been published. Current research demonstrated that FT may have positive effects in liver surgery [10-13], but most of the present evidence is based on nonrandomized retrospective studies and the effectiveness of FT programs has not been studied extensively in hepatectomy.

In an effort to clarify the role of FT programs in liver resection, Coolsen and colleagues published a systematic review of two randomized controlled trials (RCTs), three case-control studies and one retrospective case series [14]. They demonstrated that FT programs reduced the length of hospital stay without compromising morbidity, mortality, or readmission rates in liver resection. Recently, Hughes et al. [15] published another systematic update for FT versus standard care in liver surgery. Nine studies were included in their review: two RCTs and seven casecontrol studies. The authors conducted a meta-analysis of the two RCTs and suggested that FT programs reduced not only hospital stay following liver surgery, but also morbidity. Both reviews pointed out that more, larger RCTs, and meta-analyses are needed.

The purpose of the present meta-analysis of RCTs was to examine the latest substantive evidence of safety and efficacy of FT programs for hepatectomy when compared with traditional care.

\section{Methods}

\section{Literature Search}

Pubmed, Embase, Cochrane Central Register of Controlled Trials, and Google Scholar were searched to identify all RCTs of interest from January 1990 to June 2014. The following terms were used: 'enhanced recovery', 'fast-track', 'multimodal perioperative care', 'multimodal rehabilitation', 'ERAS', 'liver', 'hepatobiliary', 'hepatectomy', 'hepatic', 'resection', 'standard care', and 'traditional care'. Conference articles and review articles were used to identify additional relevant studies. No language restrictions were placed on the searches.

\section{Inclusion and Exclusion Criteria}

The inclusion criteria were as follows: (1) studies that reported adult patients undergoing elective open or laparoscopic liver surgery; (2) studies that compared FT programs with traditional care in liver resection; (3) studies that reported at least one of the outcomes; (4) when several studies were reported by the same institu-

Meta-Analysis of Fast-Track Programs in Hepatectomy tion and/or authors, they were selected only if there was no overlap between the results; (5) RCTs. The exclusion criteria were: (1) studies that reported emergency, non-elective, or transplantation surgery; (2) nonrandomized controlled trials; (3) studies that were not full text; (4) studies on the same patient cohorts that were reported in more than one article.

\section{Study Selection and Data Extraction}

Each study was critically reviewed by two researchers using the double-extraction method for eligibility according to our inclusion criteria. Five outcome variables were considered most relevant for our analysis: length of hospital stay, time to first flatus, operating time, intraoperative blood loss, and postoperative complications. In the case of studies published in conference abstracts, we contacted the authors to request the full text. Two reviewers independently performed the literature search, evaluation of trials, quality assessment, and data extraction according to the inclusion criteria. Discrepancies were resolved by consensus.

\section{Statistical Analysis}

The meta-analysis was performed using Revman 5.2 software (Cochrane IMS, Oxford, UK). Mean and standard deviation (SD) were imputed as described by Hozo et al. [16] if an included study provided only median and inter-quartile range. We also calculated the lower and upper ends of the range by multiplying the difference between the median and upper and lower ends of the inter-quartile range by 2 and then adding or subtracting the product from the median $[17,18]$. For categorical variables, the data were aggregated to obtain a pooled risk ratio (RR) with the $95 \%$ confidence interval (CI). For continuous variables, the pooled effect was reported as weighted mean difference (WMD) with the corresponding $95 \%$ CI. Heterogeneity was assessed using $\mathrm{I}^{2}$ and $\chi^{2}$ tests with $\mathrm{p}<$ 0.05 considered significant. Potential sources of heterogeneity were explored by carrying out sensitivity analyses. A random effects model was used for meta-analysis of the outcomes in the included trials. Forest plots were constructed with $\mathrm{p}<0.05$ considered significant.

Assessment of Quality and Bias Risk of the Included Studies

The quality of all the included RCTs was assessed by two authors using the Cochrane risk of bias tool [19], which includes seven specific items: random sequence generation; allocation concealment; blinding of participants; incomplete outcome data; personnel and outcome assessors; selective outcome reporting; and other bias.

\section{Results}

\section{Search Results}

A total of 312 publications were screened and six potentially eligible RCTs were identified. However, two of them were excluded, as no data on the required outcomes was available, or because of an overlap of authors. This left a total of four RCTs that were included in the final analysis (fig. 1). 
Table 1. Characteristics of studies included in this meta-analysis

\begin{tabular}{lllllll}
\hline Study & Year & $\begin{array}{l}\text { Sample size } \\
\text { (FT/TC) }\end{array}$ & $\begin{array}{l}\text { Age, years } \\
\text { (FT/TC) }\end{array}$ & $\begin{array}{l}\text { Child-Pugh class (A/B) } \\
\text { FT }\end{array}$ & Type of surgery \\
\hline Jones et al. [20] & 2013 & $46 / 45$ & $64 / 67$ (median) & NR & NR & Segmentectomy, minor resection \\
\hline Ni et al. [21] & 2013 & $80 / 80$ & $48.4 / 50.1$ (mean) & $77 / 3$ & $79 / 1$ & $\begin{array}{l}\text { Segmentectomy, right hepatectomy, } \\
\text { left hepatectomy }\end{array}$ \\
\hline Zhang et al. [22] & 2011 & $41 / 40$ & $46 / 45$ (mean) & $33 / 8$ & $34 / 6$ & Segmentectomy, half liver resection \\
\hline Fan et al. [23] & 2011 & $20 / 20$ & $44.1 / 48.7$ (mean) & $13 / 7$ & $15 / 5$ & hepatolobectomy, half liver resection \\
\hline
\end{tabular}

FT group = Fast-track group; TC group = traditional care group; NR = not report .

\section{Study Characteristics and Methodological Quality}

Characteristics of the four RCTs [20-23] included in our meta-analysis are presented in table 1. All studies were published between 1990 and 2014 and examined a total of 372 patients: 187 were allocated to an FT program; 185 received traditional care. Elements included in FT surgery programs are shown in table 2 . Figure 2 summarizes the risk of bias assessment in the included studies, most of which were of moderate quality.

\section{Hospital Stay}

All four studies [20-23] (372 patients) examined this outcome measure. There was significant heterogeneity among the trials $\left(\mathrm{I}^{2}=88 \% ; \mathrm{p}<0.001\right)$. In the randomeffects models, patients in FT programs had a hospital stay of 2.32 days less than those who received traditional care in the perioperative period of hepatectomy (WMD -2.32 ; $95 \%$ CI, -3.54 to $-1.11 ; \mathrm{p}<0.001$; fig. 3 ). When we conducted a sensitivity analysis, the heterogeneity still existed.

\section{Time to First Flatus}

Only two trials $[21,23]$ contributed to the combined analysis of the time to first flatus. There was no significant heterogeneity among the trials $\left(\mathrm{I}^{2}=0 \% ; \mathrm{p}=0.75\right)$. In the random-effects models, patients undergoing the FT program had a time to first flatus of one day less than those receiving traditional care perioperatively (WMD -0.99 ; $95 \% \mathrm{CI},-1.15$ to -0.84 ; $\mathrm{p}<0.001$; fig. 4 ).

\section{Operating Time}

Three studies [21-23] collected data on operating time. The heterogeneity test showed heterogeneity in the operating times of the three studies $\left(\mathrm{I}^{2}=71 \% ; \mathrm{p}=0.03\right)$. The random-effects model showed no significant differ-

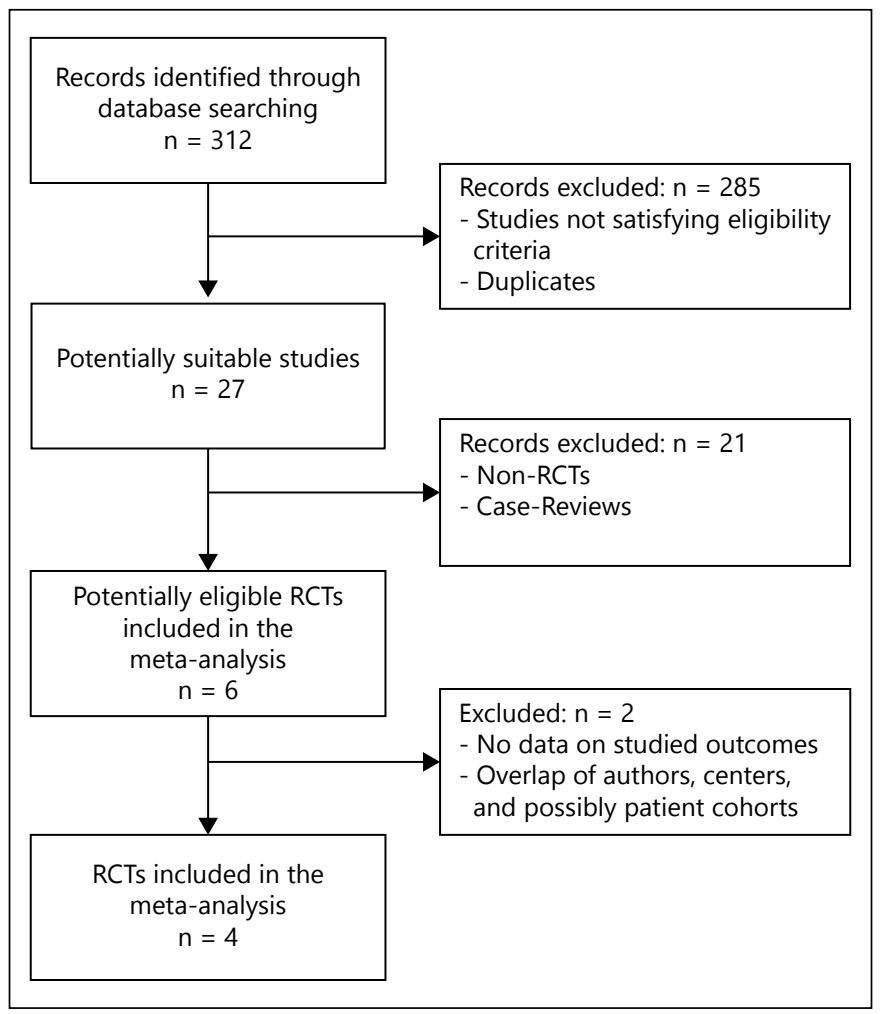

Fig. 1. Flow chart illustrating the study selection process.

ence between both groups for operating time (WMD $1.00 ; 95 \% \mathrm{CI},-19.73$ to $21.74 ; \mathrm{p}=0.92$; fig. 5). Therefore, in the sensitivity analysis, the heterogeneity did not exist.

\section{Intraoperative Blood Loss}

Data on intraoperative blood loss were available for three studies [20,21,23]. There was no significant heterogeneity among the trials $\left(\mathrm{I}^{2}=0 \% ; \mathrm{p}=0.5\right)$. The random- 
Table 2. Elements included in fast-track program

\begin{tabular}{|c|c|c|c|c|c|c|c|c|c|}
\hline Study & $\begin{array}{l}\text { Avoid } \\
\text { bowel prep }\end{array}$ & $\begin{array}{l}\text { Avoid anaesthetic } \\
\text { pre-med }\end{array}$ & $\begin{array}{l}\text { Antibiotic } \\
\text { prophylaxis }\end{array}$ & $\begin{array}{l}\text { Ileus } \\
\text { avoidance }\end{array}$ & $\begin{array}{l}\text { Multimodal } \\
\text { analgesic }\end{array}$ & $\begin{array}{l}\text { Early } \\
\text { feeding }\end{array}$ & $\begin{array}{l}\text { Early } \\
\text { mobilization }\end{array}$ & Other & $\begin{array}{l}\text { Elements, } \\
\mathrm{n}\end{array}$ \\
\hline Jones et al. [20] & + & + & + & + & + & + & + & + & 19 \\
\hline Zhang et al. [22] & + & + & + & - & + & + & + & + & 9 \\
\hline Fan et al. [23] & - & - & - & - & + & + & + & + & 15 \\
\hline
\end{tabular}

$+=$ Element explicitly listed in the fast-track surgery programs; - = element not explicitly listed in the fast-track surgery programs.

Fig. 2. Risk of bias summary in the included

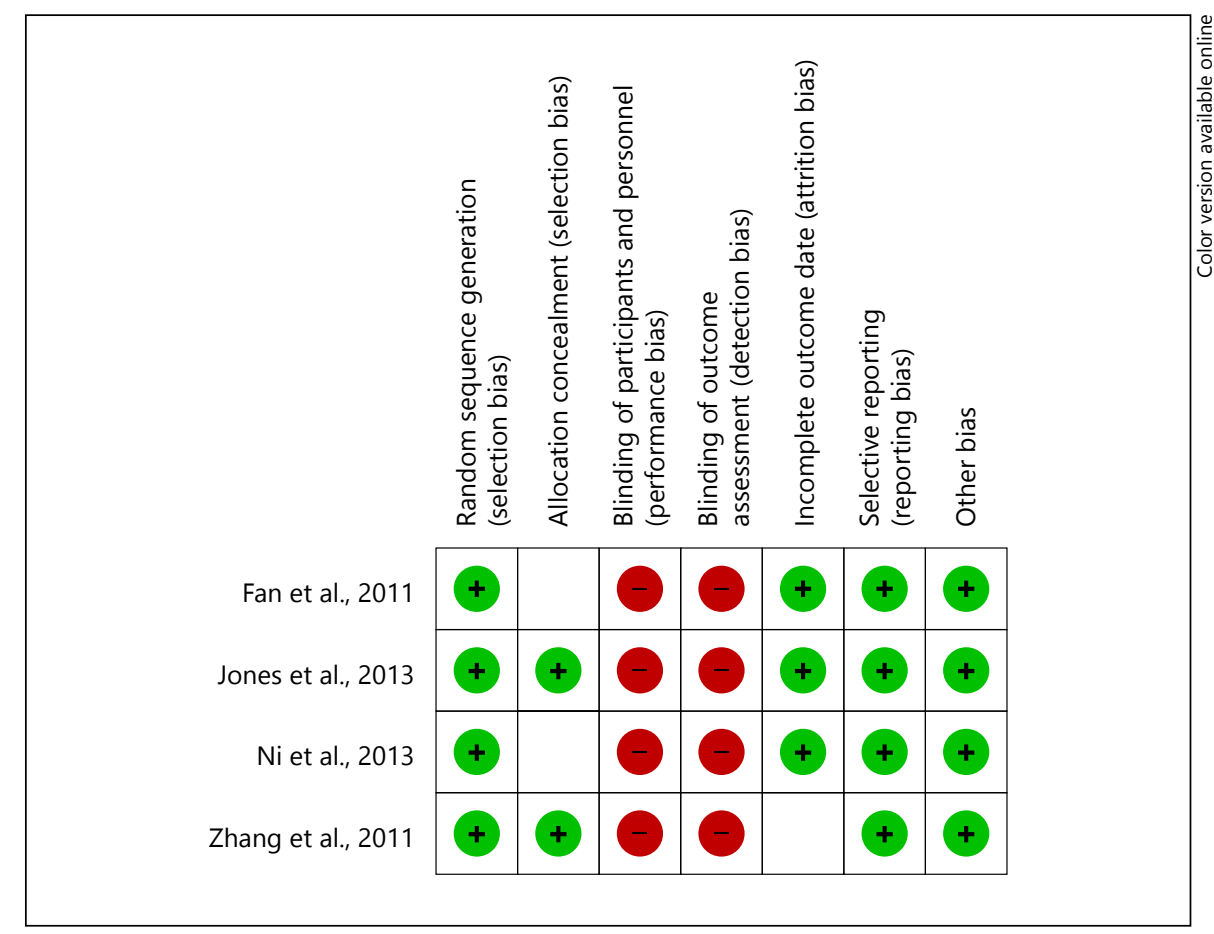
studies.

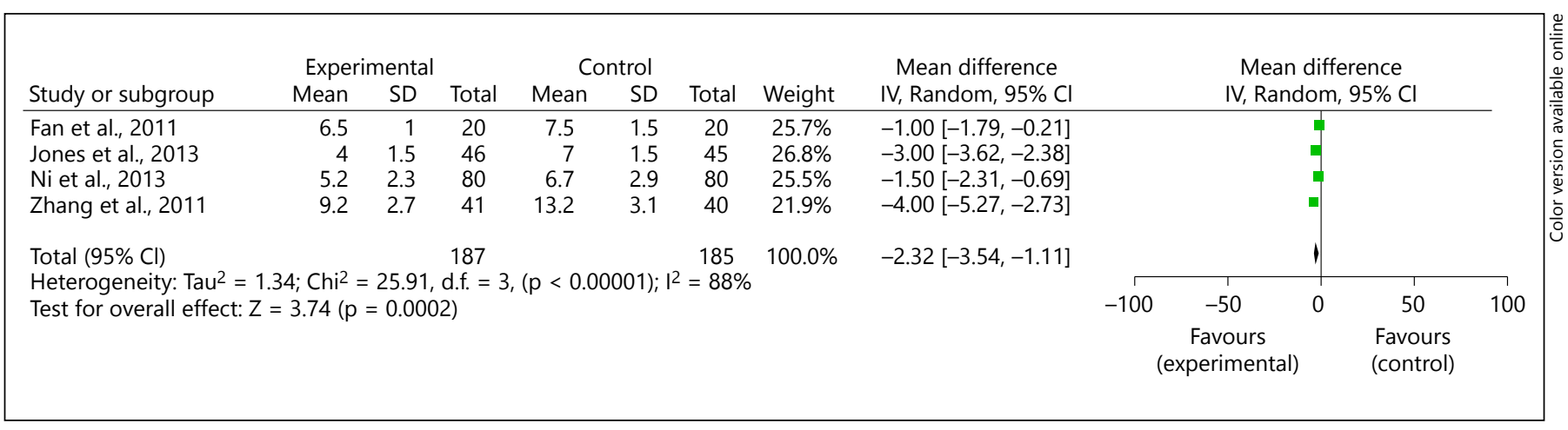

Fig. 3. Forest plot of fast-track program vs. traditional care for hospital stay.

Meta-Analysis of Fast-Track Programs in Hepatectomy 


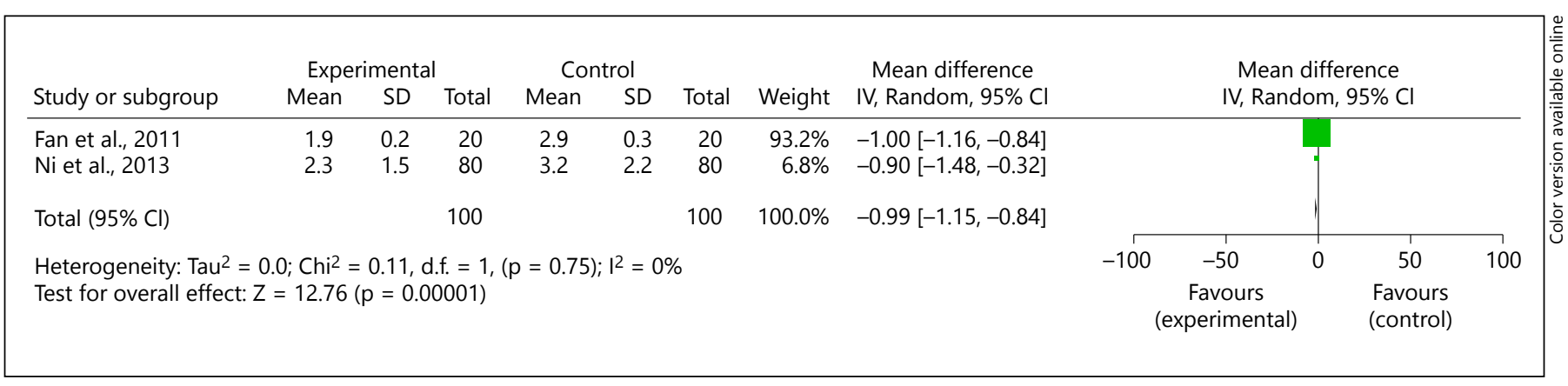

Fig. 4. Forest plot of fast-track program vs. traditional care for time to first flatus.

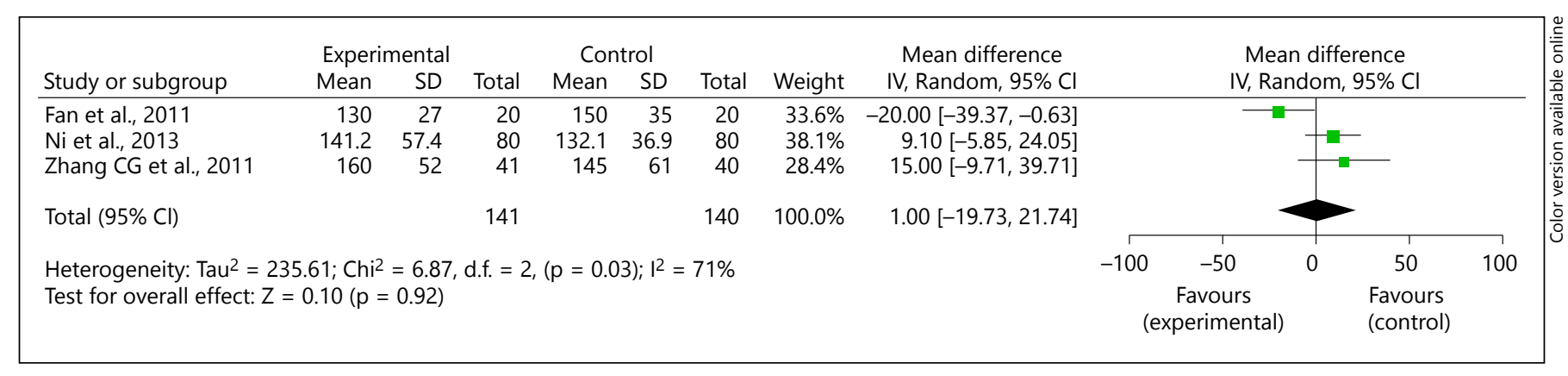

Fig. 5. Forest plot of fast-track program vs. traditional care for operative time.

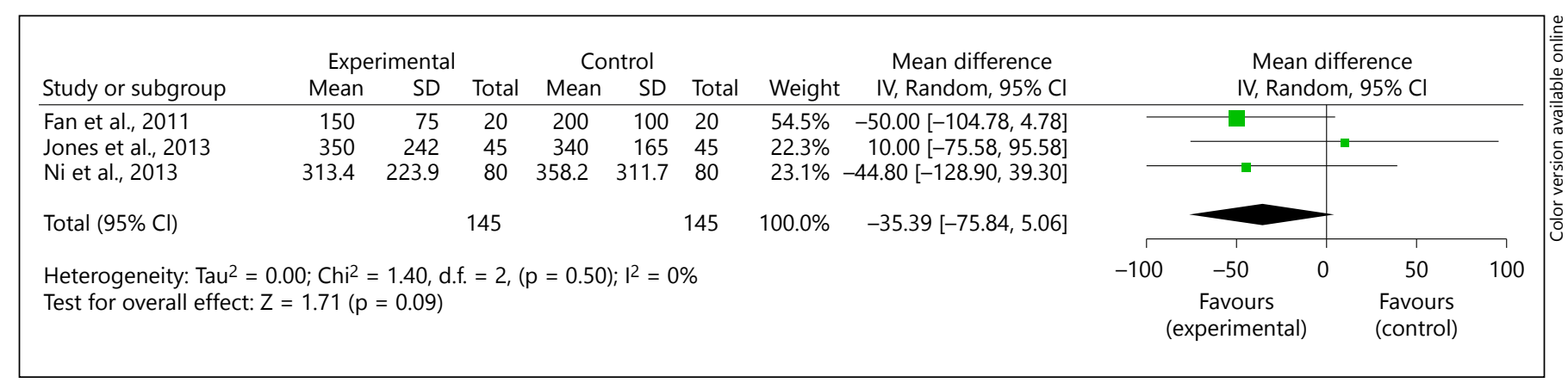

Fig. 6. Forest plot of fast-track program vs. traditional care for intraoperative blood loss.

effects model showed no significant difference between the FT and the traditional care group for intraoperative blood loss (WMD -35.39 ; 95\% CI, -75.84 to 5.06 ; $\mathrm{p}=$ 0.09 ; fig. 6).

\section{Postoperative Complications}

All four trials [20-23] (372 patients) reported the rate of postoperative complications after hepatectomy. There was no significant heterogeneity among the trials $\left(\mathrm{I}^{2}=\right.$ $0 \% ; \mathrm{p}=0.76)$. The proportion of patients who developed complications was $20.9 \%(39 / 187)$ in the FT group, and
$31.4 \%(58 / 185)$ in the traditional care group. Pooled results detected a statistical difference between the groups (RR 0.66; 95\% CI, 0.47 to 0.93; $\mathrm{p}=0.02$; fig. 7 ).

\section{Discussion}

The present study is the largest meta-analysis based on RCTs of the effect of FT programs in hepatectomy. The results of our study suggest that the implementation of an FT program reduced the time to first flatus and postop- 


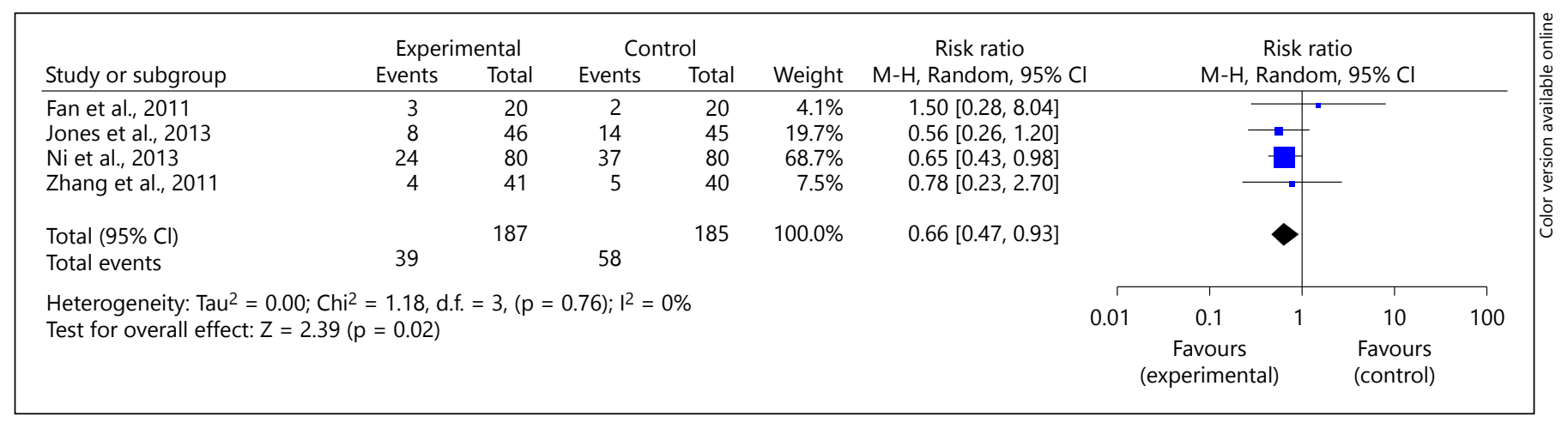

Fig. 7. Forest plot of fast-track program vs. traditional care for postoperative complication rate.

erative complications in patients undergoing liver resection surgery compared to traditional care; FT also seemed to shorten the length of hospital stay. At the same time, no significant differences were found for operating time and intraoperative blood loss between the two patient groups. These results show that FT programs potentially enhance recovery after hepatectomy without compromising patient safety.

FT programs are often used in major operations that involve a high stress response and a long convalescence [24], including elective colorectal surgery and liver resection. It is well established that FT programs can reduce mortality, length of hospitalization, readmission rate, and perioperative complications $[25,26]$. Previous studies have also indicated that patients undergoing liver resection within FT programs have a potential to achieve shorter hospital stays [21, 27]. In our meta-analysis, the pooled data from four RCTs demonstrated shorter hospital stays in patients with liver resection in an FT program compared to the traditional care group. However, there was heterogeneity for this outcome. Conducting a sensitivity analysis, we found that only two studies [20, 22] caused heterogeneity in the clinical outcome of hospital stay. One reason could be the different patient populations examined. The two studies showing greater heterogeneity included patients with liver cancer, but also patients with liver abscess, gallstones, or hepatic cysts. In contrast, the other two studies $[21,23]$ were conducted exclusively on patients with liver cancer. Furthermore, patients in the study reported by Jones et al. [20] were older, and the authors did not describe the patients' liver function grade.

Our meta-analysis revealed that the time to first flatus was shorter for patients in the FT programs than for those receiving traditional care. Although time to flatus is an

Meta-Analysis of Fast-Track Programs in Hepatectomy objective indicator, the results suggest that FT was more beneficial for recovery of the gastrointestinal function. Shorter time to first flatus could result in earlier resumption of enteral nutrition, and subsequently earlier discharge from the hospital [28]. In addition, it is well established that FT can attenuate the inflammatory response and postoperative stress [29-31]. Therefore, shorter time to first flatus and hospital stay in the FT group may also be due to a combination of these effects.

Our study revealed no significant difference for operating time between the two groups. Longer operating time is associated with more complications [32, 33], longer hospital stay [33], and higher costs [33]. Even though the FT programs for the studies included in our analysis all involved intraoperative management items, the operating time was not affected. It is possible that other factors, such as maturity of surgery skills, have contributed to this observation. Therefore, further studies are required to confirm these findings.

There was a tendency toward lower intraoperative blood loss in patients undergoing hepatic surgery in FT programs. However, the difference compared to the traditional care group was not statistically significant. FT programs contain an element of restriction of fluid intake during operation. Minimizing the blood loss during liver surgery should reduce postoperative morbidity and mortality [34-36]. Increased central venous pressure has been shown to be associated with increased intraoperative blood loss during hepatic resection [37]. All trials covered in our study reported that reduction of fluid intake in the intraoperative period was part of the care management. Therefore, a reduction in the amount of fluid administered during operation for patients with hepatic disease is desirable.

Many complications may occur after hepatectomy. Relatively common complications were found in this 
study, including wound infection, pneumonia, bile leak, and ileus. Our meta-analysis revealed that there is a tendency of lower incidence of postoperative complications in patients who underwent hepatic surgery within FT programs. The lower inflammatory response may have contributed to this result.

Some limitations of this study should be acknowledged. First, the methodological quality of the included RCTs was moderate. Second, the number of patients included in the present trials was relatively small, which may have compromised the internal validity. Third, the outcomes of the FT programs may have been influenced by the learning curve for the surgeons, and by the fact that the elements of the FT programs were not the same in all studies. Furthermore, large heterogeneity was detected for the outcome hospital stay. The degree of between trial heterogeneity present may affect the quality and legitimacy of the results obtained [38]. Lastly, none of the included RCTs was double blinded. It is very difficult to conduct double-blinded studies in this area, because of the different strategies applied in FT programs compared to traditional liver surgeries.
In conclusion, this meta-analysis showed that FT programs could reduce the time to first flatus and postoperative complications after hepatectomy. This may have led to shorter hospital stay, which was also observed. There was no significant difference with respect to operating time and intraoperative blood loss. However, the current meta-analysis provides only limited evidence suggesting that FT programs are more beneficial than traditional perioperative care without compromising patient safety. Additional large, well-constructed RCTs are necessary to draw more robust conclusions.

\section{Acknowledgments}

We would like to thank Professor Jie-Shou Li for his help in setting up FT programs in China. We also thank all authors of the publications included in this study for their contributions.

\section{Disclosure Statement}

The authors have nothing to disclose.

\section{References}

$>1$ Wilmore DW, Kehlet H: Management of patients in fast track surgery. BMJ 2001;322: 473-476.

2 Kehlet H: Fast-track colorectal surgery. Lancet 2008;371:791-793.

-3 Kehlet H, Wilmore DW: Evidence-based surgical care and the evolution of fast-track surgery. Ann surg 2008;248:189-198.

4 Wang G, Jiang ZW, Xu J, Gong JF, Bao Y, Xie LF, Li JS: Fast-track rehabilitation program vs conventional care after colorectal resection: a randomized clinical trial. World J Gastroenterol 2011;17:671-676.

5 Muehling B, Schelzig H, Steffen P, Meierhenrich R, Sunder-Plassmann L, Orend KH: A prospective randomized trial comparing traditional and fast-track patient care in elective open infrarenal aneurysm repair. World J Surg 2009;33:577-585.

6 Arsalani-Zadeh R, ElFadl D, Yassin N, MacFie J: Evidence-based review of enhancing postoperative recovery after breast surgery. Br J Surg 2011;98:181-196.

7 Magheli A, Knoll N, Lein M, Hinz S, Kempkensteffen C, Gralla O: Impact of fast-track postoperative care on intestinal function, pain, and length of hospital stay after laparoscopic radical prostatectomy. J Endourol 2011;25:1143-1147.

-8 Scott NB, McDonald D, Campbell J, Smith $\mathrm{RD}$, Carey AK, Johnston IG, James KR, Breusch SJ: The use of enhanced recovery af- ter surgery (ERAS) principles in Scottish orthopaedic units - an implementation and follow-up at 1 year, 2010-2011: a report from the Musculoskeletal Audit, Scotland. Arch Orthop Trauma Surg 2013;133:117-124.

-9 MacKay G, O’Dwyer PJ: Early discharge following liver resection for colorectal metastases. Scott Med J 2008;53:22-24.

10 Van Dam RM, Hendry PO, Coolsen MM, Bemelmans $\mathrm{MH}$, Lassen $\mathrm{K}$, Revhaug A, Fearon KC, Garden OJ, Dejong CH; Enhanced Recovery After Surgery (ERAS) Group: Initial experience with a multimodal enhanced recovery programme in patients undergoing liver resection. Br J Surg 2008; 95:969-975.

11 Stoot JH, Van Dam RM, Busch OR, van Hillegersberg R, De Boer M, Olde Damink SW, Bemelmans $\mathrm{MH}$, Dejong $\mathrm{CH}$; Enhanced Recovery After Surgery (ERAS) Group: The effect of a multimodal fast-track programme on outcomes in laparoscopic liver surgery: a multicentre pilot study. HPB (Oxford) 2009; 11:140-144.

12 Lin DX, Li X, Ye QW, Lin F, Li LL, Zhang QY: Implementation of a fast-track clinical pathway decreases postoperative length of stay and hospital charges for liver resection. Cell Biochem Biophys 2011;61:413-419.

13 Zhu L, Li J, Dong X, Liu X, Bao Z, Feng J, Yu $Y$, Zhang Y, Wang Z, Wang Z: Hospital costs and length of hospital stay for hepatectomy in patients with hepatocellular carcinoma: results of a prospective case series. Hepatogastroenterology 2010;58:2052-2057.

14 Coolsen MM, Wong-Lun-Hing EM, van Dam RM, van der Wilt AA, Slim K, Lassen K, Dejong $\mathrm{CH}$ : A systematic review of outcomes in patients undergoing liver surgery in an enhanced recovery after surgery pathways. $\mathrm{HPB}$ (Oxford) 2013;15:245-251.

15 Hughes MJ, McNally S, Wigmore SJ: Enhanced recovery following liver surgery: a systematic review and meta-analysis. HPB (Oxford) 2014;16:699-706.

16 Hozo SP, Djulbegovic B, Hozo I: Estimating the mean and variance from the median, range, and the size of a sample. BMC Med Res Methodol 2005;5:13.

-17 Liu T, Li L, Korantzopoulos P, Goudevenos JA, Li G: Meta-analysis of association between C-reactive protein and immediate success of electrical cardioversion in persistent atrial fibrillation. Am J Cardiol 2008;101: 1749-1752.

18 Li MZ, Xiao LB, Wu WH, Yang SB, Li SZ: Meta-analysis of laparoscopic versus open colorectal surgery within fast-track perioperative care. Dis Colon Rectum 2012;55:821827.

19 Higgins J, Green S: Cochrane handbook for systematic reviews of interventions version 5.0.2 (updated September 2009). The Cochrane Collaboration, 2009 (2010). 
20 Jones C, Kelliher L, Dickinson M, Riga A, Worthington T, Scott MJ, Vandrevala T, Fry $\mathrm{CH}$, Karanjia N, Quiney N: Randomized clinical trial on enhanced recovery versus standard care following open liver resection. $\mathrm{Br} \mathrm{J}$ Surg 2013;100:1015-1024.

-21 Ni CY, Yang Y, Chang YQ, Cai H, Xu B, Yang F, Lau WY, Wang ZH, Zhou WP: Fast-track surgery improves postoperative recovery in patients undergoing partial hepatectomy for primary liver cancer: a prospective randomized controlled trial. Eur J Surg Oncol 2013; 39:542-547.

22 Zhang CG, Wang QB, Zhang GD, Zhou CJ, Liu Y: Application of fast track surgery in hepatolobectomy. Chin J Pract Med 2011;38:3336.

23 Fan XJ, Tan HY, Xiao YM, Long Y, Liao B, Meng CG: Application of fast track surgery in perioperative management of patients with primary hepatic cancer. Chin J Gen Surg 2011;7:007.

24 Varadhan KK, Lobo DN, Ljungqvist O: Enhanced recovery after surgery: the future of improving surgical care. Crit Care Clin 2010; 26:527-547.

25 Kehlet H, Wilmore DW: Multimodal strategies to improve surgical outcome. Am J Surg 2002;183:630-641.

26 Keller DS, Delaney CP: The role of enhanced recovery pathways in the setting of minimally invasive colorectal surgery. Semin Colon Rectal Surg 2013;24:7-13.
7 Ntinas A, Kardassis D, Konstantinopoulos I, Kottos P, Manias A, Kyritsi M, Zilianiaki D, Vrochides D: Duration of the thoracic epidural catheter in a fast-track recovery protocol may decrease the length of stay after a major hepatectomy: a case control study. Int J Surg 2013; 11:882-885.

28 Jiang L, Yang KH, Guan QL, Cao N, Chen Y, Zhao P, Chen YL, Yao L: Laparoscopy-assisted gastrectomy versus open gastrectomy for resectable gastric cancer: an update metaanalysis based on randomized controlled trials. Surg Endosc 2013;27:2466-2480.

29 Kehlet H: Multimodal approach to control postoperative pathophysiology and rehabilitation. Br J Anaesth 1997;78:606-617.

-30 Muehling BM, Ortlieb L, Oberhuber A, Orend $\mathrm{KH}$ : Fast track management reduces the systemic inflammatory response and organ failure following elective infrarenal aortic aneurysm repair. Interact Cardiovasc Thorac Surg 2011;12:784-788.

31 Pavelescu D, Mirea L, Păduraru M, Beuran M, Chiotoroiu A, Grinţescu I: The role of multimodal analgesia in the decrease of postoperative surgical stress response in major neoplastic thoraco-abdominal surgery. Chirurgia (Bucur) 2011;106:723-728.
2 Catanzarite T, Saha S, Pilecki MA, Kim JY, Milad M: The effect of operative time on perioperative morbidity after laparoscopic hysterectomy. Obstet Gynecol 2014;123:123S.

33 Huang KH, Kaplan AL, Carter SC, Lipsitz SR, $\mathrm{Hu}$ JC: The impact of radical prostatectomy operative time on outcomes and costs. Urology 2014;83:1265-1271.

34 Poon RT, Fan ST, Lo CM, Liu CL, Lam CM, Yuen WK, Yeung C, Wong J: Improving perioperative outcome expands the role of hepatectomy in management of benign and malignant hepatobiliary diseases: analysis of 1,222 consecutive patients from a prospective database. Ann surg 2004;240:698-708.

-35 Hammond JS, Guha IN, Beckingham IJ, Lobo DN: Prediction, prevention and management of postresection liver failure. Br J Surg 2011; 98:1188-1200.

36 Zimmitti G, Roses RE, Andreou A, Shindoh J, Curley SA, Aloia TA, Vauthey JN: Greater complexity of liver surgery is not associated with an increased incidence of liver-related complications except for bile leak: an experience with 2,628 consecutive resections. J Gastrointest Surg 2013;17:57-64; discussion 64-65.

- 37 McNally SJ, Revie EJ, Massie LJ, McKeown DW, Parks RW, Garden OJ, Wigmore SJ: Factors in perioperative care that determine blood loss in liver surgery. HPB (Oxford) 2012;14:236-241.

- 38 Ng TT, McGory ML, Ko CY, Maggard MA: Meta-analysis in surgery: methods and limitations. Arch Surg 2006;141:1125-1130. 